\title{
Comparison of the Effects of Three Different Methods in Reducing Primary Postpartum Hemorrhage
}

\author{
Zumrut Bilgin ${ }^{1}$ (D), Nuran Komurcu ${ }^{2}$ (D) \\ ${ }^{1}$ Marmara University, Health Science Faculty, Midwifery Department, Istanbul, Turkey. \\ ${ }^{2}$ Istanbul Aydın University, Health Science Faculty, Nursing Department, Istanbul, Turkey. \\ Correspondence Author: Zumrut Bilgin \\ E-mail: zumrutbilgin45@gmail.com
}

Received: 22.05.2020 Accepted: 15.10.2020

\begin{abstract}
Objective: The aim of this study was to determine the effects of three different methods in reducing primary postpartum hemorrhage.

Methods: The study was carried out in Istanbul/Turkey with 150 people at a maternity hospital. The participants were assigned to the external circular fundus massage (ECFM) ( $n=50)$, external bimanual fundus compression (EBFC) $(n=50)$ and control (C) ( $n=50)$ groups with the simple randomization method. The women in the experiment groups of external circular fundus massage or external bimanual uterus fundus compression received intervention for one hour in the postpartum period. At the 6th postpartum hour, the hemogram values and total lochia amount of all women were measured.

Results: The mean \pm standard deviation (SD) age of the women was $24.77 \pm 4.40$ years, $63.3 \%$ were having their first birth, and $47.3 \%$ gained weight between 11 and $16 \mathrm{~kg}$ in their pregnancy. There was no significant difference between the groups in terms of the mean \pm SD Hb at the 6th postpartum hour (ECFM group=11.5 \pm 1.1 ; EBFC Group $=11.7 \pm 3.6$; C group $=11.4 \pm 1.0 \mathrm{~g} / \mathrm{dL}, \mathrm{F}=0.371, \mathrm{p}=0.691$ ). In comparison to the ECFM and $C$ groups, the 2nd postpartum hour visual analog scale (VAS) score of the EBFC group was found to be significantly lower ( $p<0.05$ ).

Conclusion: The hemoglobin and thrombocyte levels at the 6th postpartum hour were higher in the EBFC group in comparison to the other groups, while the hematocrit value decreased more. Since EBFC is effective in reducing postpartum pain, it is recommended to be applied especially to women with postpartum pain.
\end{abstract}

Keywords: Hemoglobin, delivery, postpartum hemorrhage, randomized controlled, uterus massage

\section{INTRODUCTION}

Postpartum hemorrhage (PPH) is defined as blood loss over $500 \mathrm{~mL}$ in vaginal delivery and over $1000 \mathrm{~mL}$ in post-cesarean delivery. Primary postpartum hemorrhage occurs within the first 24 hours (early), and the bleeding that occurs after 24 hours is called secondary (late) postpartum hemorrhage. Primary postpartum hemorrhages occur in $4-6 \%$ of births, and hemorrhagic shock and sudden death develop when bleeding is not controlled. One-half of maternal deaths occur due to bleeding in the first 24 hours postpartum (1-4).

The World Health Organization (WHO) reported that, in 2015, an estimated 303,000 maternal deaths were occurring worldwide (5). In Turkey, according to the Health Statistics Yearbook 2018 News Bulletin, in 2017, the maternal mortality rate was reported as 14.6 per 100,000 live births (6). Primary postpartum hemorrhages usually occur as a result of uterine atony, placenta retention and delivery (vagina and cervix) due to laceration. The most important cause of primary postpartum hemorrhage is uterine atony $(75-90 \%)(2,7)$.
In the postpartum period, various pharmacological and nonpharmacological interventions are performed to achieve uterine contraction and prevent bleeding. One of the routine non-drug interventions is external uterine massage. Uterine massage reduces the amount of postpartum hemorrhage by stimulating prostaglandin release and contraction of the uterus. In a study, it was stated that uterine massage reduces blood loss and uterotonic requirement. External uterus fundus massage may be applied in various ways (external circular fundus massage-ECFM and external bimanual fundus compression-EBFC) (8-10).

Although it is stated that uterine massage increases contractions and accelerates uterine involution and prevents atony, there are limited and conflicting studies in the literature showing the effectiveness of massage. The aim of this study was to determine the effects of three different methods in reducing primary postpartum hemorrhage. 


\section{METHODS}

\subsection{Study Design}

This study was planned as a single-blind, randomized controlled trial (Figure 1). After the research was planned, a power analysis was performed using the $\mathrm{G} *$ Power 3.1 program. According to the results obtained from the research, as a result of the standard deviation obtained from the postpartum $\mathrm{Hb}$ mean, the mean difference was 0.90 , the degree of freedom (df) was 2, the effect size was calculated as 0.3 , and it was observed that $90 \%$ power was obtained on the $\alpha=0.05$ level $(11,12)$. A total of 224 persons were included in the study considering data losses. However, the study was completed with 150 person, including 50 in each group. The eligibility criteria for the participants in this study are shown in Table 1.

Table 1. Eligibility Criteria for Participants

Inclusion criteria $\quad$ Exclusion criteria

- Age range: $18-40$

- Gestation: 37-41

- Nulliparous or multiparous

- Intrapartum hemoglobin

value of at least $11 \mathrm{~g} /$

$\mathrm{dL}$ (Center for Disease

Control=CDC recommendation)

- Fetus in cephalic

presentation

- Single healthy fetus

- Vaginal delivery

- Estimated fetal weight: 2500-

4000 gr.
- Those with any medical or obstetric complication (coagulation defect,

placenta previa, etc.)

- Developing any postpartum complications

- Those whose babies were transferred

to the newborn unit

- Cesarean births

- Cervical tear cases

- Those who cannot collect their pads

- Women without postpartum $6^{\text {th }}$-hour

hemogram

results

- Those who were administered postpartum analgesics and additional uterotonics

- Women who did not volunteer for

participation in the study.

CONSORT Flow Diagram

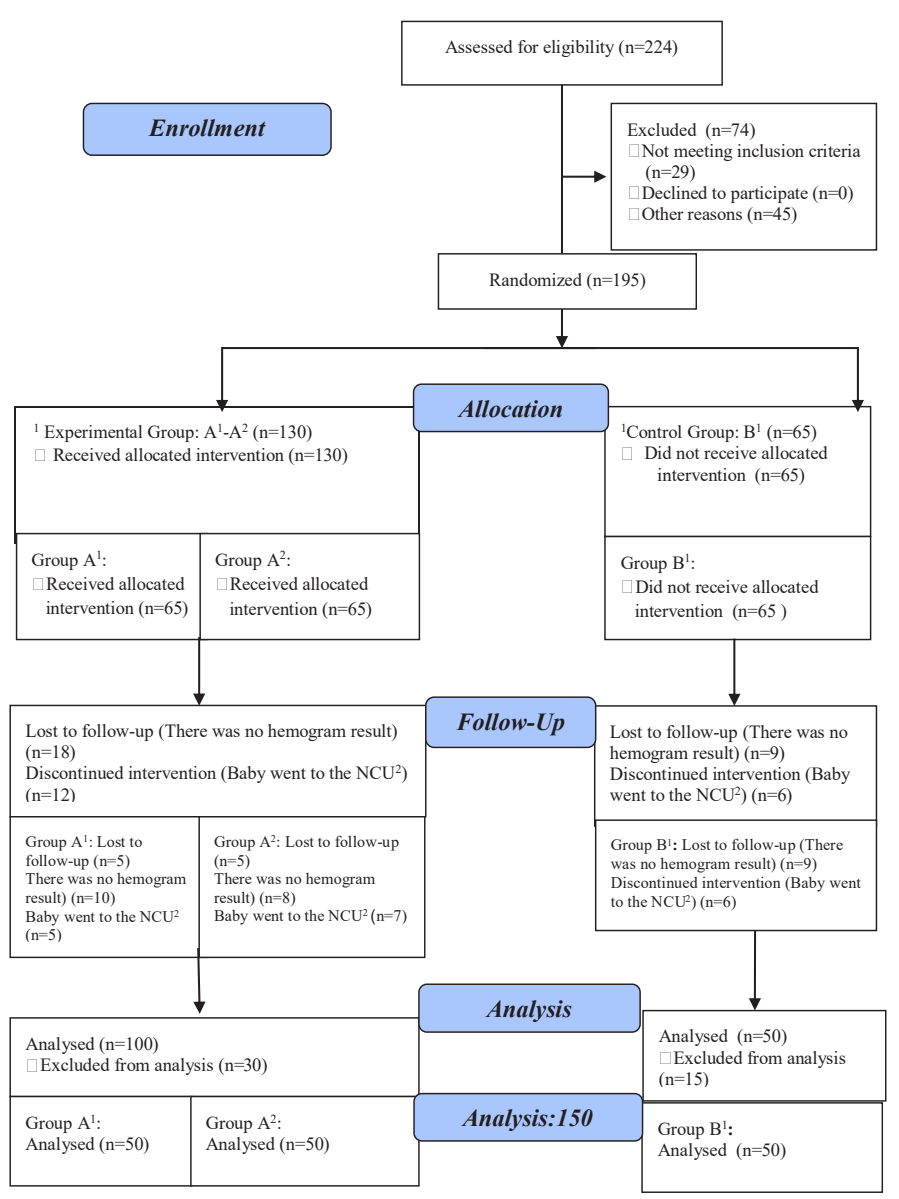

Figure 1. CONSORT Flow Diagram of Randomized Controlled Trial ${ }^{1}$ Experimental Group A1- A2 and Control Group B1 and comparator arms ${ }^{2}$ Newborn care unit 


\subsection{Settings and Participants}

The study was conducted in Istanbul, Turkey with women at a maternity hospital between February and November 2015. The hospital where the research was conducted has a capacity of 352 beds. At this hospital, approximately 7321 deliveries, 4303 vaginal deliveries and 3018 caesarean section deliveries occur annually. Randomization was performed using a computer. Envelopes containing the randomization results were kept closed in the delivery room. Block randomization was used to equilibrate the groups (13). The consort flow diagram of the research is shown in Figure 1.

\subsection{Data Collection Tools}

Participant diagnostic information form: All forms used in the study were prepared by the researcher using the literature $(5,9,14)$. This form included the socio-demographic and obstetric characteristics of the participants and questions about the second stage of labor (episiotomy, the way the placenta is removed, the baby's weight, etc.).

Postpartum information form: The vital signs of the participants, the pad used, the lochia clot status, the urination status and the time the newborn was breastfed were recorded (at the end of the $1^{\text {st }}-2^{\text {nd }}-6^{\text {th }}$ postpartum hours). Venous blood (intrapartum and postpartum at the $6^{\text {th }}$ hour) was also taken for the hemogram sample.

Standard pad: A standard sterile pad (weighed in a digital weighing instrument) was given to each woman at the delivery desk. All pads used at the end of the second postpartum hour were weighed. At the end of the second hour, the women were given standard sterile pads weighed to the extent that they could be used for at least 6 hours postpartum (at least 4 pads) and a pouch to collect the pads. At the end of the postpartum 6 hours, all used pads were weighed. The total weight of bleeding was recorded by subtracting the final total weight from the initial total weight.

Bed protector: A standard bed protector (weighed on a digital weighing instrument) used by the clinic was placed on the bed sheet. At the end of the postpartum second hour, the bed protector was weighed (pre-weighed) and the total amount of lochia was recorded. Bleeding controls were performed at the end of the second hour. In the following hours, the women did not need a mattress protector.

Sensitive scale (digital): A digital precision scale (Dikomsanfec digital weighing instrument (https://www.orsa.gen.tr/ FEC) was used for weighing the pads. These instruments were being calibrated every 6 months.

\subsection{Data Collection}

The participant diagnostic information forms were filled in by the face-to-face interview method. The delivery processes of the women participating in the study were monitored. Immediately after the placenta was out and episiotomy or laceration repair was completed, the woman was given a pre-weighed pad and bed protector.

Postpartum information forms were filled at the postpartum clinic. The women's vital signs (at the $1^{\text {st }}-2^{\text {nd }}-6^{\text {th }}$ postpartum hours) were measured by the researcher. The postpartum pain levels (at the $1^{\text {st }}-2^{\text {nd }}-6^{\text {th }}$ postpartum hours) were evaluated by the Visual Analog Scale (VAS) and recorded.

\subsection{Intervention}

The experiment 1 group was applied external uterine massage at the end of the first postpartum hour. The experiment 2 group was applied external bimanual fundus compression at the end of the first postpartum hour.

External Circular Fundus Massage (ECFM): At the end of the first postpartum hour, the women were administered ECFM by the researcher in one hour, for 60-second durations repeated every 15 minutes. During the massage, a gentle circular rubbing motion was performed gently down the fundus uteri with one hand, while the lower uterus was supported on the level of the symphysis pubis with the other hand.

External Bimanual Fundus Compression (EBFC): At the end of the first postpartum hour, the women were administered EBFC by the researcher in one hour, for 60 -second durations repeated every 15 minutes. During the massage, the fundus uteri was gently pressed down with one hand, the lower part of the uterus was supported on the symphysis pubis level with the other hand, and the fundus was compressed between the two hands. Care was taken not to disturb the woman in both massages.

Care was taken not to impair the comfort of the woman during the massage application. After each massage, pad control was performed and evaluated in terms of lochia clots. The perineum was also evaluated in terms of edema, redness and hematoma. The control group received no intervention other than routine care and follow-up. Venous blood was collected at the $2^{\text {nd }}$ and $6^{\text {th }}$ prepartum and postpartum hours for hemogram measurements from all women in the three groups. All pads and bed protectors used by the woman (previously weighed) were weighed again with a digital weighing device at the end of the $2^{\text {nd }}$ and $6^{\text {th }}$ hours. According to the clinical protocol, 20 units of oxytocin in 500 cc $5 \%$ dextrose fluid were routinely given to all women giving vaginal delivery $(5,15)$.

\subsection{Ethical Considerations}

In order to conduct the research, first of all, ethical approval from the hospital's ethics committee (the decision of the ethics committee of the Zeynep Kamil Training and Research Hospital of the Health Sciences University (date 02/06/2015/ No:7) and the permission of the institution were obtained. Before starting the study, written consent was obtained from the participants who agreed to participate in the study. It was declared that the ethical principles of the 1975 Declaration of Helsinki would be followed. 


\subsection{Statistical Analysis}

The data obtained in the study were analyzed using the Statistical Package for the Social Sciences (SPSS) demo program. The qualitative categorical data were analyzed by Chi-squared test, the normally distributed continuous data were analyzed by One-Way ANOVA and t-test. Additionally, descriptive statistics (mean, standard deviation, frequency and percentage) were calculated. The results were evaluated in a $95 \%$ confidence interval and on a $<0.05$ significance level (16).

\section{RESULTS}

The individual and obstetric characteristics of the participants in each group were similar and are shown in Table 2.

Table 2. Individual and Obstetric Characteristics of the Women

\begin{tabular}{|c|c|c|c|c|}
\hline Characteristics & $\begin{array}{l}\text { ECFM group } \\
\qquad(n=50)\end{array}$ & $\begin{array}{l}\text { EBFC group } \\
(n=50)\end{array}$ & $\begin{array}{l}\text { Cgroup } \\
(n=50)\end{array}$ & $\begin{array}{l}X^{2} / p \\
\text { value }\end{array}$ \\
\hline \multicolumn{5}{|l|}{ Age (years) } \\
\hline $18-24$ & $28(56.0)$ & $25(50.0)$ & $29(58.0)$ & \multirow{3}{*}{$\begin{array}{l}1.770 \\
0.787\end{array}$} \\
\hline $25-30$ & $16(32.0)$ & $20(40.0)$ & $14(28.0)$ & \\
\hline$>31$ & $6(12.0)$ & $5(10.0)$ & $7(14.0)$ & \\
\hline \multicolumn{5}{|l|}{ Education } \\
\hline Primary school & $20(40.0)$ & $16(32.0)$ & $21(42.0)$ & \multirow{3}{*}{$\begin{array}{l}1.793 \\
0.774\end{array}$} \\
\hline $\begin{array}{l}\text { Secondary/ } \\
\text { high school }\end{array}$ & $25(50.0)$ & $26(52.0)$ & $22(44.0)$ & \\
\hline University & $5(10.0)$ & $8(16.0)$ & $7(14.0)$ & \\
\hline \multicolumn{5}{|c|}{ Number of pregnancies } \\
\hline One & $32(64.0)$ & $27(54.0)$ & $27(54.0)$ & \multirow{2}{*}{$\begin{array}{l}1.363 \\
0.506\end{array}$} \\
\hline Two-four & $18(36.0)$ & $23(46.0)$ & $23(46.0)$ & \\
\hline \multicolumn{5}{|l|}{ Number of births } \\
\hline Nulliparparous & $38(76.0)$ & $28(56.0)$ & $29(58.0)$ & \multirow{2}{*}{$\begin{array}{l}5.225 \\
0.073\end{array}$} \\
\hline Primiparparous & $12(24.0)$ & $22(44.0)$ & $21(42.0)$ & \\
\hline \multicolumn{5}{|c|}{ Gestational week } \\
\hline $37-39$ & $15(30.0)$ & $16(32.0)$ & $21(42.0)$ & \multirow{2}{*}{$\begin{array}{l}1.825 \\
0.422\end{array}$} \\
\hline $40-41$ & $35(70.0)$ & $34(68.0)$ & $29(58.0)$ & \\
\hline \multicolumn{5}{|c|}{ Total weight gain during pregnancy } \\
\hline $5-10$ & $18(36.0)$ & $9(18.0)$ & $14(28.6)$ & \multirow{3}{*}{$\begin{array}{l}5.870 \\
0.273\end{array}$} \\
\hline $11-16$ & $22(44.0)$ & $28(56.0)$ & $21(42.0)$ & \\
\hline 17 and over & $10(20.0)$ & $13(26.0)$ & $15(30.6)$ & \\
\hline \multicolumn{5}{|l|}{ Episiotomy } \\
\hline Applied & $45(90.0)$ & $42(84.0)$ & $39(78.0)$ & \multirow{2}{*}{$\begin{array}{l}2.679 \\
0.285 \\
\end{array}$} \\
\hline Not applied & $5(10.0)$ & $8(16.0)$ & $11(22.0)$ & \\
\hline \multicolumn{5}{|c|}{ Birth weight of newborn (g) } \\
\hline $2500-3000$ & $7(14.0)$ & $14(28.0)$ & $12(24.0)$ & \multirow{3}{*}{$\begin{array}{l}3.741 \\
0.442\end{array}$} \\
\hline $3001-3499$ & $30(60.0)$ & $27(54.0)$ & $25(50.0)$ & \\
\hline $3500-4000$ & $13(26.0)$ & $9(18.0)$ & $13(26.0)$ & \\
\hline
\end{tabular}

ECFM: external circular fundus massage; EBFC: external bimanual fundus compression; C: control

In the study, there was no difference between the groups in terms of prepartum and postpartum $\mathrm{Hb}$ values being 11-12 $\mathrm{g} / \mathrm{dL}$ or $>12.1 \mathrm{~g} / \mathrm{dL}$ (Table 3 ).

There was no difference between the groups in terms of the prepartum and postpartum Htc values of the groups being below $34.0 \%$ or $>34.1 \%$.
There was no difference between the groups in terms of the prepartum postpartum Plt values being below $\leq 150 \mathrm{~K} / \mathrm{mm}^{3}$ or $>151 \mathrm{~K} / \mathrm{mm}^{3}$ (Table 3).

Table 3. Comparison of Hemogram and Lochia Values of Groups

\begin{tabular}{|c|c|c|c|c|c|c|}
\hline \multicolumn{2}{|l|}{ Variables } & $\begin{array}{l}\text { ECFM } \\
\text { group } \\
(n=50)\end{array}$ & $\begin{array}{l}\text { EBFC } \\
\text { group } \\
(n=50)\end{array}$ & $\begin{array}{l}\text { C group } \\
(n=50)\end{array}$ & $\begin{array}{c}\text { Total } \\
(n=150)\end{array}$ & \multirow{2}{*}{$\begin{array}{l}X^{2} / p \\
\text { value } \\
\text { n (\%) } \\
0.164\end{array}$} \\
\hline \multirow{2}{*}{$\begin{array}{l}\text { Prepartum } \\
\mathrm{Hb}\end{array}$} & $11-12$ & $21(42.0)$ & $20(40.0)$ & $22(44.0)$ & $63(42.0)$ & \\
\hline & & $29(58.0)$ & $30(60.0)$ & $28(560)$ & $87(58.0)$ & 0.921 \\
\hline \multirow{2}{*}{$\begin{array}{l}\text { Postpartum } \\
6^{\text {th }} \text { hour } \mathrm{Hb}\end{array}$} & & $30(60.0)$ & $39(78.0)$ & $36(72.0)$ & $105(70.0$ & \multirow{2}{*}{$\begin{array}{l}4.000 \\
0.135\end{array}$} \\
\hline & $>12.1$ & $20(40.0)$ & $11(22.0)$ & $14(28.0)$ & $45(30.0$ & \\
\hline \multirow{2}{*}{$\begin{array}{l}\text { Prepartum } \\
\mathrm{Htc}\end{array}$} & $\leq 34.0$ & $1(2.0)$ & $4(8.0)$ & $6(12.0)$ & $11(7.3)$ & \multirow{2}{*}{$\begin{array}{l}3.728 \\
0.155\end{array}$} \\
\hline & $>34.1$ & $49(98.0)$ & $46(92.0)$ & $44(88.0)$ & 139 (92.7) & \\
\hline \multirow{2}{*}{$\begin{array}{l}\text { Postpartum } \\
6^{\text {th }} \text { hour Htc }\end{array}$} & $\leq 34.0$ & $23(46.0)$ & $26(52.0)$ & $25(50.0)$ & $74(49.3)$ & \multirow{2}{*}{$\begin{array}{l}0.373 \\
0.830 \\
\end{array}$} \\
\hline & $>34.1$ & $27(54.0)$ & $24(48.0)$ & $25(50.0)$ & $76(50.7)$ & \\
\hline \multirow{2}{*}{$\begin{array}{l}\text { Prepartum } \\
\text { Plt }\end{array}$} & & $10(20.0)$ & $7(14.0)$ & & & \multirow{2}{*}{$\begin{array}{l}2.024 \\
0.363\end{array}$} \\
\hline & $>151$ & $40(80.0)$ & $43(86.0)$ & $45(90.0)$ & $128(85.3)$ & \\
\hline \multirow{2}{*}{$\begin{array}{l}\text { Postpartum } \\
6^{\text {th }} \text { hour Plt }\end{array}$} & & $8(16.0)$ & $5(10.0)$ & & $17(11.3)$ & \multirow{2}{*}{$\begin{array}{l}1.725 \\
0.422 \\
\end{array}$} \\
\hline & $>151$ & $42(84.0)$ & $45(90.0)$ & $46(92.0)$ & $133(88.7)$ & \\
\hline \multirow{2}{*}{$\begin{array}{l}\text { Postpartum } \\
6^{\text {th }} \text { hour } \\
\text { total lochia } \\
\text { (g) }\end{array}$} & & $44(88.0)$ & $46(92.0)$ & & $134(89.3)$ & \multirow[b]{2}{*}{$\begin{array}{l}0.560 \\
0.756\end{array}$} \\
\hline & $\geq 100$ & $6(12.0)$ & $4(8.0)$ & $6(12.0)$ & $16(10.7)$ & \\
\hline
\end{tabular}

ECFM: external circular fundus massage; EBFC: external bimanual fundus compression; C: control

There was no statistically significant difference between the groups in terms of the amount of lochia at the $6^{\text {th }}$ postpartum hour being $<100 \mathrm{~g}$ or $100 \mathrm{~g}(\mathrm{p}>0.05)$ (Table 3).

In the study, the mean \pm SD prepartum $\mathrm{Hb}$ of the groups $(12.4 \pm 0.9 ; 12.3 \pm 0.8 ; 12.4 \pm 0.9$, respectively) and the mean $6^{\text {th }}$ postpartum hour $\mathrm{Hb}$ (respectively: $11.5 \pm 1.1 ; 11.7 \pm 3.6$; $11.4 \pm 1.0)$ values were compared, and no difference was observed between the groups in terms of the mean $\mathrm{Hb}$ values ( $p>0.05)$ (Table 4).

The mean \pm SD prepartum Htc values of the groups $\left(37.7 \pm 2.7 ; 37.6 \pm 2.8 ; 37.5 \pm 2.8\right.$, respectively) and the mean $6^{\text {th }}$ postpartum hour Htc (respectively: $34.6 \pm 3.0 ; 34.1 \pm 2.8 ; 34.3$ \pm 2.8 ) values were compared, and the difference between the groups in terms of the mean Htc values was not significant ( $p>0.05$ ) (Table 4).

In the study, the mean \pm SD prepartum Plt of the groups (respectively: $212.4 \pm 67.7 ; 230.4 \pm 60.4 ; 216.0 \pm 46.6$ ) and the mean \pm SD $6^{\text {th }}$ postpartum hour Plt $(215.1 \pm 58.7 ; 227.3 \pm 55.4$; $218.9 \pm 47.7$, respectively) values were compared, and there was no significant difference between the groups in terms of the mean Plt values ( $p>0.05$ ) (Table 4).

The mean $6^{\text {th }}$ postpartum hour lochia amount $(\mathrm{g})$ values of the groups (respectively: $110.7 \pm 48.3 ; 108.1 \pm 43.7 ; 111.9 \pm 63.9$ ) were compared, and there was no significant difference between the groups in terms of the amount of lochia ( $p>0.05$ ) (Table 4). 
In the study, the mean \pm SD $2^{\text {nd }}$ postpartum hour VAS scores of the groups (respectively: $1.7 \pm 1.7 ; 0.6 \pm 1.1 ; 1.4 \pm 1.9$ ) were compared, and a statistically significant difference was found between the groups in terms of the mean VAS scores ( $p$ $<0.05$ ) (Table 4). There was no significant difference between the groups in terms of the other hourly VAS mean scores.

Table 4. Comparison of Hemogram Values, Amount of Lochia and VAS Score of the Groups

\begin{tabular}{|l|c|c|c|c|}
\hline \multicolumn{1}{|c|}{ Variables } & $\begin{array}{c}\text { TCFM group } \\
(\mathbf{n}=50)\end{array}$ & $\begin{array}{c}\text { TBFC group } \\
(\mathbf{n}=50)\end{array}$ & $\begin{array}{c}\text { C group } \\
(\mathbf{n}=50)\end{array}$ & \multirow{2}{*}{ F/ p value } \\
\cline { 2 - 4 } & $\begin{array}{c}\text { Mean } \pm \text { SD } \\
(\text { Min-Max) }\end{array}$ & $\begin{array}{c}\text { Mean } \pm \text { SD } \\
(\text { Min-Max) }\end{array}$ & $\begin{array}{c}\text { Mean } \pm \text { SD } \\
(\text { Min-Max) }\end{array}$ & \\
\hline Prepartum & $12.4 \pm 0.9$ & $12.3 \pm 0.8$ & $12.4 \pm 0.9$ & 0.098 \\
Hb & $(11.0-14.5)$ & $(11.0-15.0)$ & $(11.0-14.6)$ & 0.907 \\
\hline Postpartum & $11.5 \pm 1.1$ & $11.7 \pm 3.6$ & $11.4 \pm 1.0$ & 0.371 \\
$6^{\text {th }}$ hour Hb & $(7.8-13.6)$ & $(9.1-36.2)$ & $(9.3-13.8)$ & 0.691 \\
\hline Prepartum & $37.7 \pm 2.7$ & $37.6 \pm 2.8$ & $37.5 \pm 2.8$ & 0.112 \\
Htc & $(33.7-43.3)$ & $(32.4-47.2)$ & $(32.3-43.5)$ & 0.894 \\
\hline Postpartum & $34.6 \pm 3.0$ & $34.1 \pm 2.8$ & $34.3 \pm 2.8$ & 0.408 \\
$6^{\text {th }}$ hour Htc & $(28.4-41.3)$ & $(27.0-41.2)$ & $(27.0-40.4)$ & 0.666 \\
\hline Prepartum & $212.4 \pm 67.7$ & $230.4 \pm 60.4$ & $216.0 \pm 46.6$ & 1.300 \\
Plt & $(101.0-387.0)$ & $(100.0-364.0)$ & $(121.0-301.0)$ & 0.276 \\
\hline Postpartum & $215.1 \pm 58.7$ & $227.3 \pm 55.4$ & $218.9 \pm 47.7$ & 0.666 \\
$6^{\text {th }}$ hour PIt & $(111.0-400.0)$ & $(88.0-345.0)$ & $(116.0-319.0)$ & 0.515 \\
\hline Postpartum & $110.7 \pm 48.3$ & $108.1 \pm 43.7$ & $111.9 \pm 63.9$ & 0.066 \\
$6^{\text {th }}$ hour total & $(41.0-250.0)$ & $(30.0-237.0)$ & $(12.0-368.0)$ & 0.936 \\
lochia (gr) & & & & \\
\hline Postpartum & $1.7 \pm 1.7$ & $0.6 \pm 1.1$ & $1.4 \pm 1.9$ & 5.834 \\
$2^{\text {th }}$ hour VAS & $(0.0-7.0)$ & $(0.0-4.0)$ & $(0.08 .0)$ & 0.004 \\
\hline
\end{tabular}

ECFM: external circular fundus massage; EBFC: external bimanual fundus compression; C: control; VAS: visual analog scale; SD: standard deviation

As a result of further analysis, the postpartum VAS score of the EBFC group was found to be significantly lower in comparison to the ECFM group ( $t=3.645, p<0.05$ ). Compared to the control group, the postpartum VAS score of the EBFC group was significantly lower $(t=2.443, p<0.05)$. No excessive bleeding or atony occurred in any of the groups.

\section{DISCUSSION}

Different strategies have been published in the literature to prevent PPH. Active management of the third stage of labor consists of a group of interventions, such as administration of prophylactic oxytocin after birth and uterine massage $(2,5,17)$. Blood loss at birth affects the hemogram levels. The degree of postpartum blood loss can be determined by measuring hemogram values and the amount of lochia $(18,19)$.

In the study, there was no difference between the groups in terms of the prepartum and postpartum $\mathrm{Hb}$ values being 11$12 \mathrm{~g} / \mathrm{dL}$ or $>12.1 \mathrm{~g} / \mathrm{dL}$ (Table 3). Hofmeyr et al. concluded that application of postpartum uterus massage reduces the bleeding rate by $80 \%$ (9). In another study, no difference was found between the groups in terms of the hemoglobin value with and without uterine massage, while the mean blood loss in the massage group was found to be lower (8). In the study by Chen et al., one group received uterine massage together with oxytocin, the other group received only uterine massage, and no difference was found between the groups in terms of blood loss in the first 2 hours after delivery (20). In another study, intramuscular oxytocin, continuous uterine massage and both methods together were applied, and uterine massage was reported to be less effective than oxytocin in reducing postpartum hemorrhage (21). Chantrapitak compared lower uterine segment compression and non-compression applied groups, and lower blood loss was found in the women who were administered lower uterine segment compression (14). In another study, a group that was administered active management at the third stage of labor and a group that received active management + massage were compared, and it was reported that blood loss was reduced in the women who received active management + massage $(22,23)$. The differences in the results of studies are thought to be due to the use of additional medication and non-drug methods to prevent bleeding, application of episiotomy and removal of the placenta by active traction.

There was no difference between the groups in terms of the prepartum and postpartum $\mathrm{Htc}$ values of the groups being below $\leq 34.0 \%$ or $>34.1 \%$ (Table 3 ). Yazıcıoglu et al. compared groups with and without manual compression of the uterine isthmus after the placenta emerged during elective caesarean section and found that the Htc value was lower in patients who did not undergo intervention on the first postpartum day (12). Chantrapitak et al. reported no significant difference between the Htc values of the group where massage was applied and the group where it was not applied (8). It was stated in the literature that both analgesic and anxiolytic effects of massage stimulate oxytocin release $(23,24,25)$. In this study, it was observed that the massage applied to the women in the EBFC group had a relaxing effect. There was no significant difference between the groups in terms of the prepartum and postpartum Plt values being below $\leq 150 \mathrm{~K}$ / $\mathrm{mm}^{3}$ or $>151 \mathrm{~K} / \mathrm{mm}^{3}$ (Table 3 ). In the study by Chantrapitak et al., in terms of the postpartum thrombocyte values, there was no significant difference between the groups receiving and not receiving massage (8). Platelets are an important parameter in monitoring postpartum hemorrhage and determining treatment efficacy. Additionally, while $\mathrm{Hb}$ and $\mathrm{Htc}$ values decrease at the onset of bleeding, an increase in platelet values is thought to be a sign of healthy hemostasis physiology.

No statistically significant difference was found between the groups in terms of the amount of lochia at the $6^{\text {th }}$ postpartum hour (g) (Table 3). Abdel-Aleem et al. arrived at significant results showing that uterine massage performed at the third stage of labor reduces hemorrhage in 30 minutes and 60 minutes (21). However, in this study, no difference was found between the uterine massage groups and the control group in terms of the amount of lochia. Uterine massage is not recommended for women who have been administered prophylactic oxytocin (5). 
In the study, the mean postpartum 2nd-hour VAS scores of the groups (respectively: $1.7 \pm 1.7 ; 0.6 \pm 1.1 ; 1.4 \pm 1.9$ ) were compared, and a statistically significant difference was found between the groups in terms of the mean VAS scores (Table 4). Ramasamy and Suzan found that fundal massage and alternative leg raising exercise reduced postpartum pain. Since the pressing/compression of the uterus is applied with EBFC, the effect of the woman lying prone was achieved, and the postpartum pain was reduced (26). In this study, the EBFC massage reduced the postpartum pain of the women.

\section{Limitations of Research}

This research is limited to the hospital where the data were collected. So, it is not generalizable to the entire country.

\section{CONCLUSION}

As a result of this study in which the effects of external uterine massages was discussed, the women in the group treated with EBFC had higher postpartum $6^{\text {th }}$-hour $\mathrm{Hb}$ and $\mathrm{Plt}$ mean values in comparison to the other groups, while their mean Htc was found to be lower. The postpartum 2nd-hour VAS mean scores of the women in the group that received EBFC were significantly lower than the other groups.

Consequently, in order to reduce postpartum hemorrhage, the importance of early breastfeeding, early mobilization and frequent bladder emptying should be explained to women. External uterine fundus massages should not be applied routinely, but external uterine massages should be applied until pharmacological treatments are initiated in the atonic uterus. It is recommended to apply EBFC massage to women who have pain in the postpartum period.

Acknowledgements: Patient consent forms were completed and signed by the women.

\section{REFERENCES}

[1] Alkema L, Chou D, Hogan D, Zhang S, Moller AB, Gemmill $A$, et al. Global, regional, and national levels and trends in maternal mortality between 1990 and 2015, with scenariobased projections to 2030: a systematic analysis by the UN Maternal Mortality Estimation Inter-Agency Group. Lancet 2016;387:462 -474.

[2] Martins HEL, Souza ML, Khanum S, Naz N, Souza ACRH. The practice of nursing in the prevention and control of postpartum hemorrhage: an integrative review. American Journal of Nursing Science 2016;5:8-15.

[3] Leduc D, Senikas V, Lalonde AB, Ballerman C, Biringer A, Delaney $M$, et al. Active management of the third stage of labour: prevention and treatment of postpartum hemorrhage. JOGC 2009;31:980-993.

[4] Queensland Clinical Guideline (QCG). Primary postpartum haemorrhage. Queensland Clinical Guidelines Steering Committee Statewide Maternity and Neonatal Clinical Network (Queensland). 2018;p:2-37. Available from: URL: https://www.health.qld.gov. au/_data/assets/pdf_file/0015/140136/g-pph.pdf.
[5] World Health Organization (WHO). Trends in maternal mortality: 1990-2015:Estimates from WHO, UNICEF, UNFPA, World Bank Group and the United Nations Population Division. World Health Organization. [Updated:2015]. Available from: URL: https://www.unfpa.org/publications/trends-maternalmortality-1990-2015.

[6] T. C. Ministry of Health, General Directorate of Health Information Systems. Health statistics yearbook 2018 news newsletter. 2018;pp:1-8. Available from: URL: https://sbsgm.saglik.gov.tr/ TR,57543/saglik-istatistikleri-yilligi-2018-haber-bulteni.html.

[7] Carroli G, Mignini L. Episiotomy for vaginal birth. Cochrane Database Syst Rev. 2009;(1):CD000081. Available from: URL: https://doi.org/10.1002/14651858.CD000081.pub2.

[8] Chantrapitak W, Srijuntuek K, Wattanaluangarun R. The efficacy of lower uterine segment compression for prevention of early postpartum hemorrhage after vaginal delivery. J Med Assoc Thai 2011;94:649-656.

[9] Hofmeyr GJ, Abdel-AleemH, Abdel-Aleem MA. Uterine massage for preventing postpartumhaemorrhage. Cochrane Database Syst Rev. 2013;1:CD006431. Available from: URL: https://doi.org/10.1002/14651858.CD006431.pub3.

[10] Abedzadeh-Kalahroudi M. Prevention of postpartum hemorrhage:our options. Nurs Midwifery Stud 2015;4:e29641.

[11] Faul F, Erdfelder E, Lang AG. Buchner, A. G*Power 3: A flexible statistical power analysisprogram for the social, behavioral, and biomedical sciences. Behavior Research Methods 2007;39:175-191.

[12] Yazıcıoğlu HF, Capar S, Şevket O, Keskin S, Ateş S. Use of manual strangulation technique to reduce blood loss at elective cesarean section. Pam Med J 2014;7:27-31.

[13] Saghaei M. An overview of randomization and minimization programs for randomized clinical trials. An overview of randomization and minimization programs for randomized clinical trials. J Med Signals Sens 2011;1:55-61.

[14] Chantrapitak W, Srijanteok K, Puangsa-art S. Lower uterine segment compression for management of early postpartum hemorrhage after vaginal delivery at charoenkrung pracharak hospital. J Med Assoc Thai 2009;92:600-605.

[15] Breymann C, Honegger C, Hosli I, Surbek D. Diagnosis and treatment of iron-deficiency anaemia in pregnancy and postpartum. Arch Gynecol Obstet 2017; 296:1229-1234.

[16] Miller RL, Acton C, Fullerton DA, Maltby J. SPSS for social scientists. Martin's Press, LLC and of Palgrave Macmillan Ltd. New York, 2002;12-353. Available from: URL: http://gtu.ge/ Agro-Lib/1\%20(1).pdf.

[17] Saccone G, Caissutti C, Ciardulli A, Abdel-Aleem H, Hofmeyr GJ, Berghella $\mathrm{V}$. Uterine massage as part of active management of the third stage of labour for preventing postpartum haemorrhage during vaginal delivery: a systematic review and meta-analysis of randomised trials. BJOG 2018;125:778-781.

[18] Golmakani N, Khaleghinezhad K, Dadgar S, Hashempor $\mathrm{M}$, Baharian N. Comparing the estimation of postpartum hemorrhage using the weighting method and national guideline with the postpartum hemorrhage estimation by midwives. Iranian J Nursing Midwifery Res 2015;20:471-475.

[19] Gabrielloni MC, Armellini CJ, Barbieri M, Schirmer J. Analysis of hemorrhage at vaginal delivery by erythrocyte and hematocrit indices. Acta Paul Enferm 2014; 27:186-193.

[20] Chen M, Chang Q, Duan T, He J, Zhang L, Liu X. Uterine massage to reduce blood loss after vaginal delivery. Obstet Gynecol 2013;122:290-295. 
[21] Abdel-Aleem $H$, Singata $M$, Abdel-Aleem M, Mshweshwe $\mathrm{N}$, Williams $\mathrm{X}$, Hofmeyr GJ. Uterine massage to reduce postpartum hemorrhage after vaginal delivery. IJGO 2010;111:32-36.

[22] Yasir R, Lakhwani MB, Naz S, Ali Z. Primary postpartum hemorrhage; The effectiveness of uterine massage with active management as compared to active management alone, in the prevention at a tertiary care hospital in Karachi Pakistan. Professional Med J 2016;23:1178-1182.

[23] Nabil Aboushady RM, Khalefa El-Saidy TM, Farrag RE. Effect of uterine massage and active management during the third stage of labor on reduction of postpartum hemorrhage among high risk women. IOSR-JNHS 2018;7:46-57.

[24] Goodin BR, Ness TJ, Robbins MT. Oxytocin - A multifunctional analgesic for chronic deep tissue pain. Curr Pharm Des 2015;21:1-8.

[25] Arslan Özkan H, Bilgin Z. Postpartum kanamalar. Kanıta Dayalı Gebelik ve Doğum Yönetimi. Ankara:Nobel Tıp Kitapevleri; 2019.

[26] Ramasamy P, Suzan HL. Effectiveness of selected nursing measures on level of after birth pain among primipara mothers. Journal of Gynecology and Obstetrics 2014;2: 100105. 